\title{
New Methods Testing of Adhesion of the Coating to Sheet Metal by Bending"
}

\author{
Milan Dvořák ${ }^{1}$, Emil Schwarzer ${ }^{2}$ \\ ${ }^{1}$ Faculty of Mechanical Engineering, Brno University of Technology, Brno, Czech Republic; ${ }^{2}$ Fritzmeier Ltd., Vyškov, Czech Re- \\ public. \\ Email: dvorak.m@fme.vutbr.cz,y129121@stud.fme.vutbr.cz
}

Received January $17^{\text {th }}, 2012$; revised February $22^{\text {nd }}, 2012$; accepted March $14^{\text {th }}, 2012$

\begin{abstract}
The article is deals for new experimental equipment for effective test adhesion for selected coating STEEL, applied cold on the coated metal sheet with Al (aluminum). Explanation to the word STEEL: STEEL coating has significant anticorrosive properties and he is resistant for main oxidizing agents such as acids, alkalis, salt vapors etc. Resists temperatures to $600^{\circ} \mathrm{C}$ and create an elastic film that is resistant to abrasion, as soon as it was to complete polymerization. It is very simple to applied to metallic and nonmetallic surfaces. Dries quickly and is dry to the touch after 90 to 120 seconds. STEEL is the best possible solution anywhere, if needs arises powerful local protection against atmospheric and corrosive agents or to elevated temperatures. STEEL is also useful as a method for protect of welds on stainless steels instead of traditional staining procedures. Broad application is in automotive industry to modify the surfaces of block vehicle, car-body repairs, welds needing protection, in heating industry for example boilers, in air condition with heat exchanger and in shipping industry [1-3]. In experiments with a new test equipment is showed that for bending radius of interval from range R11 to R35 there is a change deposited coating STEEL from original coating Al and this coating was part of test metal sheet of thickness $1.5 \mathrm{~mm}$. In the next stage of solution was developed technological process, which allowed increase of adhesion coating STEEL for bending up to or maximum $180^{\circ}$ (shape U). Result of new technology is documented in article. Experiments was implementing with cooperation of the Masaryk University in Brno.
\end{abstract}

Keywords: Metal Sheet; Aluminum Coating; Adhesion; Bending; Plasma

\section{Introduction}

For field testing and evaluation of adhesion of coated sheet is characterized by great diversity of methods and procedures [4-7]. In addition to the testing procedures used to test for adhesion to metal and other coatings such as coatings adhesion test grid cut, test the resistance of the coating in Erichsen device [8-12] etc. In addition to determining the resistance of coatings made against cracking or peel the coating from steel sheet after bending test surface-treated sheet is done (making) bend test in laboratories in the $180^{\circ}$ cylindrical mandrel [13].

For testing of steel plate with coat $\mathrm{Al}$ and STEEL according to DIN EN 327/EN 101143 with ultimate tensile strength (mez pevnosti $\mathrm{v}$ tahu) $\mathrm{R}_{\mathrm{m}}=307 \mathrm{MPa}$, proof stress $\mathrm{R}_{\mathrm{p} 0.2}=154 \mathrm{MPa}$, tensibility $\mathrm{A}_{80}=43 \%$ and a thickness of $1.5 \mathrm{~mm}$ was used new graduated bending jig, (Figure 1) developed in the Institute of Engineering Technology in BUT (BRNO UNIVERSITY OF TECHNOLOGY) [1417].

*The article is supported by the grant project, VUT FSI Brno-BD 1393016 from 2009.
New graduated bending jig, its design allows testing of coated sheet (plate) of greater thickness than the currently test jig recommended from norm ČSN ISO 1519.

The JIG allows simultaneous bend five samples in the range of values of angles up to $180^{\circ}$ by using rollers through (over) cylindrical segments. They can make a "U" bends with inner radius R11, R17, R23, R29 and R35 mm.

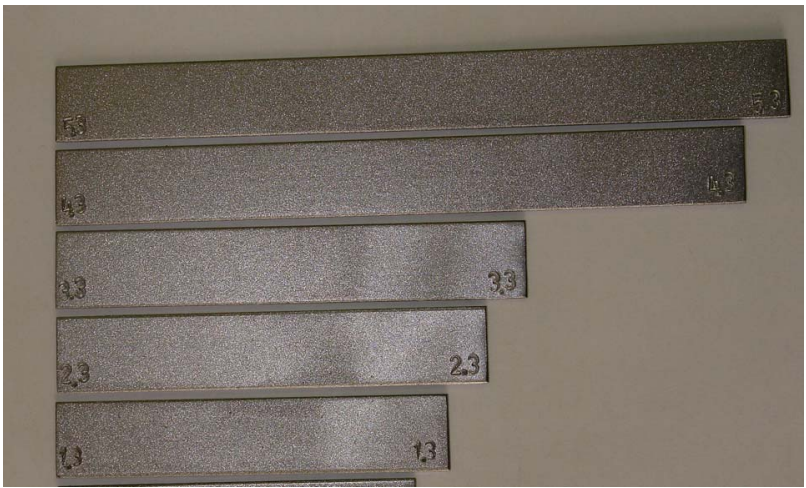

Figure 1. Selected samples before bending. 
Cylindrical segments can be easily exchanged for a different radius. Bent sample is distinct in the case of coating damage assessed visually, and if there is no apparent damage of coat, using all segments, otherwise follows the close examination of the functional coating cracks under the microscope.

The aim of the experiment was to test on the new graduated bending jig adhesion of selected steel samples with dimensions in the range of lengths from 98 to 181 $\mathrm{mm}$ and a uniform width of $18 \mathrm{~mm}$. All samples were with Al coat, to which was additionally applied coat STEEL by cold.

The JIG was designed as an assembly unit and the pulley and segments are fixed to BEND-JIG by screws and their possible rebuild on the different range of radius is easy and can be done in a short time interval. Segments were replaced by rollers, Figure 2. Design solutions in Figure 3, with segments gave a worse prediction of evaluating the quality of coating on a steel plate.

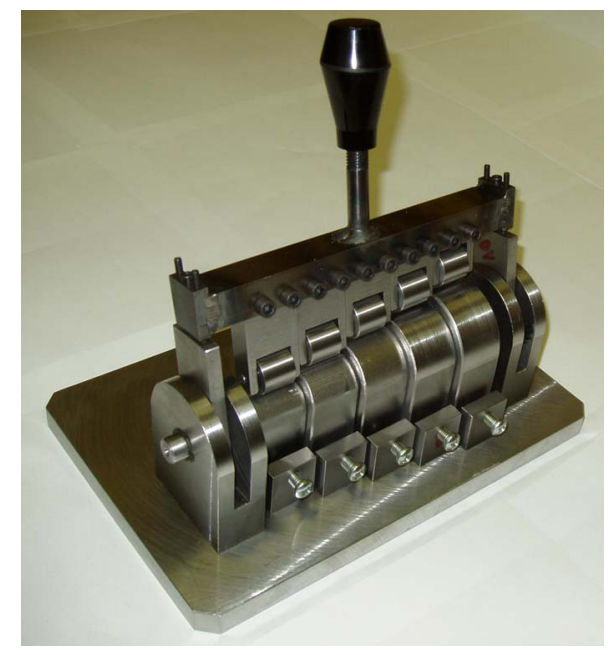

Figure 2. Photo of graduated bending jig with rollers $[14,15$, 17].

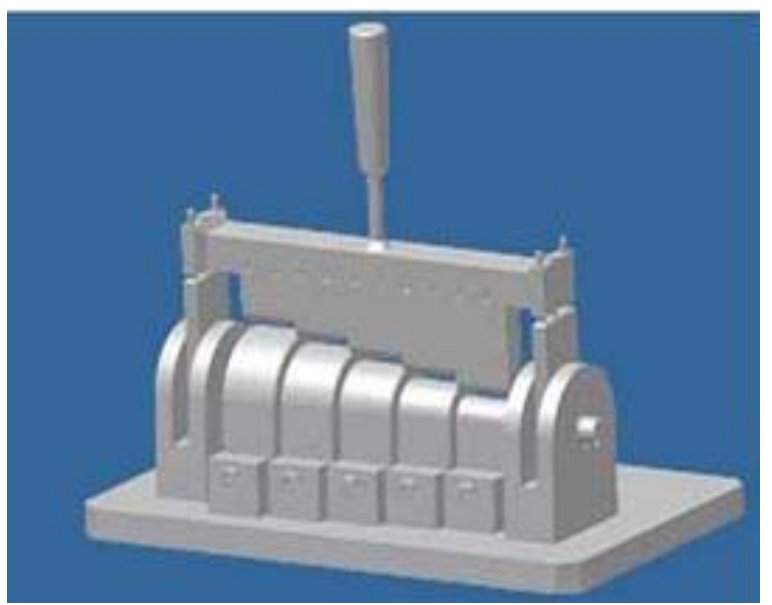

Figure 3. Model of graduated bending jig with segments [5].

\section{Test Adhesion of Coating}

Experiments were divided into two stages. In the first stage, samples were tested at five pieces without previous treatment of surface by $\mathrm{Al}$ coating by plasma jets before applying coating STEEL. Thickness originally deposited Al coating from supplier for all samples was measured by THICKNESS ELCOMETR 456 and measurement results are documented in the sample (Figure 4). Measurement of thickness was also applied to the coating STEEL which was applied on the Al coating (Figure 5).

STEEL coating serves as a surface treatment of steel (heat resistant up to $600^{\circ} \mathrm{C}$, the aesthetic effect, and increased corrosion resistance).

STEEL coating was subjected by chemical analysis and was found that coating contain $13.6 \mathrm{wt} \% \mathrm{Si}$, which strengthens the coating and contributes to the deterioration of plastic properties in shaping sheet metal (plate).

According to the supplier of company Faren Ltd. resists such as acids, salt vapors and is resistant to corrosion and atmospheric effect. It can be used for adjustment of welds in stainless steels in place of traditional pickling methods.

Before applying the coating STEEL was performed on all samples thoroughly degrease the surface with $\mathrm{Al}$ using highly effective degreaser Cleas-S.

It was found that on the basis of the bending tests in the test preparation is adhesion of coating STEEL unsuitable. When forming the bend into the shape of " $U$ " in the test preparation occurred in the interval of radii of curvature from R11 to R35 mm STEEL breach of the coating (Figure 6).

In the second stage of the experiment was used in conjunction with MU Brno multi-jet plasma system (Figure 7).

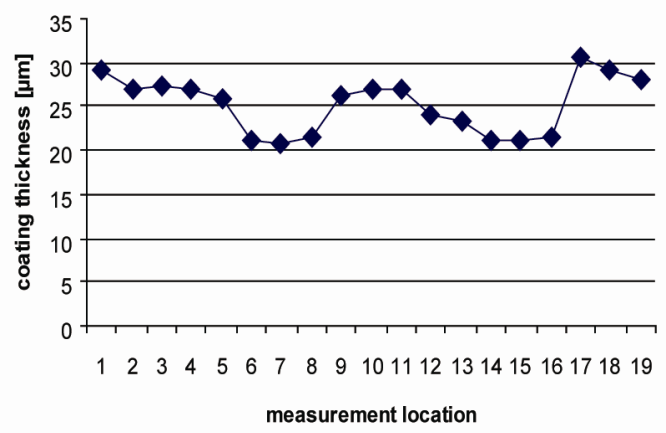

Figure 4. The thickness of Al coating on steel sheet, sample 15, side A.

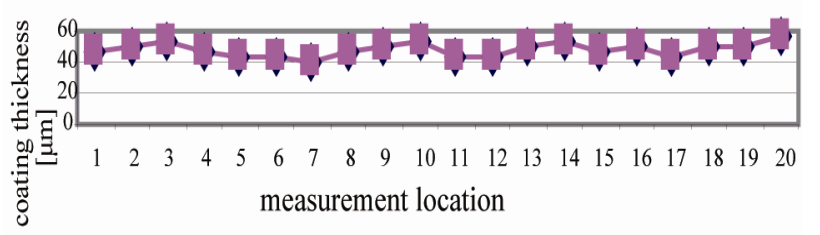

Figure 5. Thickness of coating STEEL, sample 15, side A. 


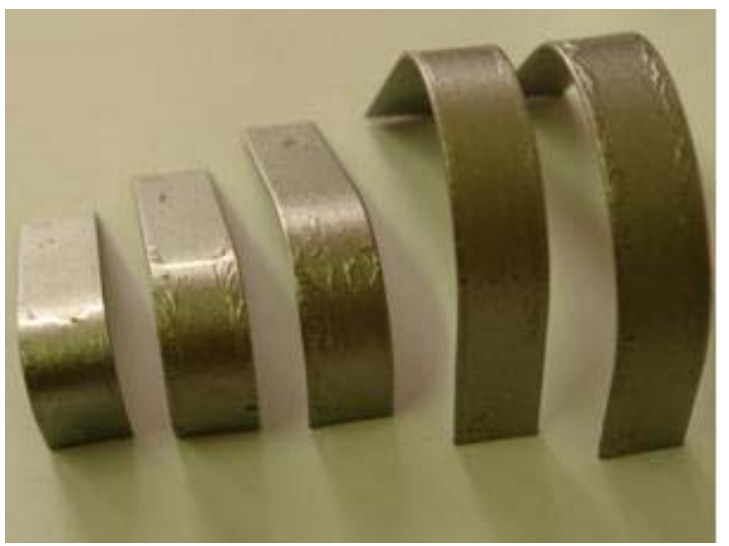

Figure 6. Photo of damaged coating STEEL after the bending without application of plasma.

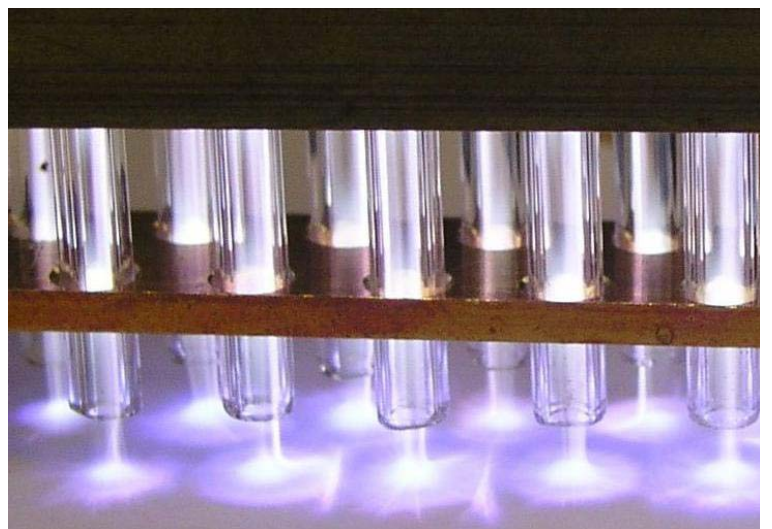

Figure 7. Sample of multi-jet system used in the experiment [11].

with a width of $100 \mathrm{~mm}$ with nineteen jets providing low-temperature and non-isometric discharge at atmospheric pressure.

The physical nature of the phenomenon of plasma multi-jet system consists of generating plasmas at atmospheric pressure.

\section{The Principle of High-Frequency Hollow Cathode (13.56 MHz)}

The basis of nozzles was used dielectric capillaries made of silica glass, which flows through the argon, including any additions.

The resulting plasma jets from the mouth cavity of the plasmic-jet into the external environment, which acts on the coated steel samples.

Discharge for the entire length of plasma channel active generated.

Absorbed power of the plasma channel was used multi-jet device according to selected working conditions in the range from $10^{2}$ to $10^{3} \mathrm{~W} \cdot \mathrm{cm}^{-2}$.

Unlike welding, electron beams, where the power density at the point of welding to $10^{9} \mathrm{~W} \cdot \mathrm{cm}^{-2}[8]$.
Thermal effects on the surface of samples can be in range from $30^{\circ} \mathrm{C}$ to $1600^{\circ} \mathrm{C}$ while maintaining non-isometric character of discharge (temperature of energy particles of $10,000 \mathrm{~K}$ ).

On the based these properties of plasma-jet system can provide a highly reactive compound with high efficiency for the chemical and physical modification of the surface material.

A suitable grouping of nozzles (jets) in linear or other formations allows cutting of large areas of test samples respectively semi-finished steel in industrial practice [18, 19].

The result of the application used multi-jet system on the test specimens with Al coated on the set of optimal parameters of plasma jets flowing out of nineteen, (knowhow process), was subsequently applied coating STEEL, which had no signs of damage after bending the sample on the graduated bending jig (Figure 8).

\section{Conclusions}

On the based of bending experiments of steel samples with a nominal thickness of $1.5 \mathrm{~mm}$, width $18 \mathrm{~mm}$ and lengths in interval from 98 to $181 \mathrm{~mm}$ of low-carbon steel according to DIN EN 327 with sprayed coatings Al thickness of $25 \pm 5 \mu \mathrm{m}$ and STEEL $47 \pm 7 \mu \mathrm{m}$ were found:

Performing of the bending on the cylindrical thorns with radii R11, R17, R23, R29 and R33 without application of plasma with a functional surface of tested coatings is impossible without their defects.

After application and optimalization of plasma parameters using the plasma system was made functional coatings for cylinder radii R29 and R33 in the test graduated bending JIG.

For smaller radii of test cylinders, i.e. there were slight defects in the coating STEEL.

Graduated bending test JIG used for experiments was newly developed and introduced for testing by bending sheet metal into the shape of " $U$ " at the Institute of

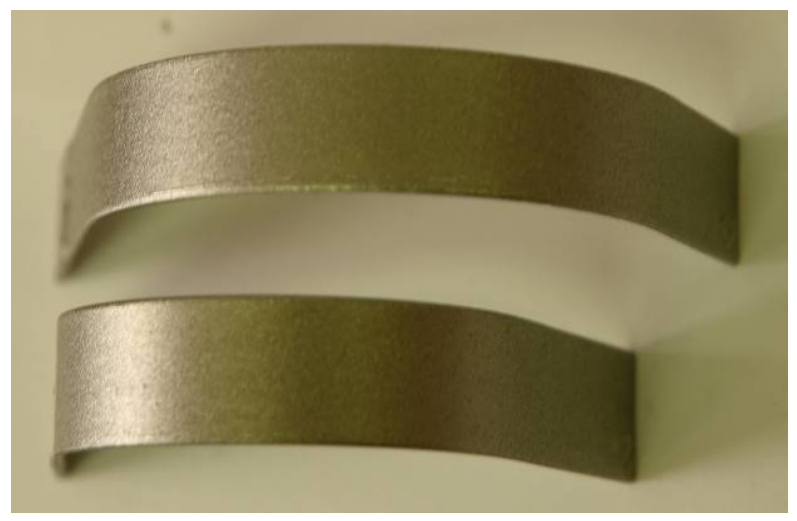

Figure 8. Photo of functional coating STEEL after the bending with the application of plasma made in graduated bending jig with rollers at BUT BRNO. 
Engineering Technology in BUT (BRNO UNIVERSITY OF TECHNOLOGY).

\section{REFERENCES}

[1] A. Sarani, A. Y. Nikiforov and C. Leys, "Low-Temperature Plasmas, Plasma Applications, Plasma Sources, Sheaths," Physics of Plasmas, Vol. 17, No. 6, 2010, pp. 063504-063511. doi:10.1063/1.3439685

[2] D. H. Shin, C. U. Bang, J. H. Kim, Y. C. Hong, H. S. Uhm, D. K. Park and K. H. Kim, "Treatment of Metal Surface by Atmospheric Microwave Plasma Jet," IEEE Transactions on Plasma Science, Vol. 34, No. 4, 2006, pp. 1241-1246. doi:10.1109/TPS.2006.876486

[3] B. M. Akram, K. M. B. Jansen, L. J. Ernst and S. Bhowmik, "Atmospheric Pressure Plasma Surface Modification of Titanium for High Temperature Adhesive Bonding," International Journal of Adhesion and Adhesives, Vol. 31, No. 7, 2011, pp. 598-604. doi:10.1016/j.ijadhadh.2011.05.009

[4] M. Marečková and M. Dvořák, "Effect of Bending on the Quality of Zinc Coating on Steel Sheet," Bratislava, 2009, pp. 67-70.

[5] ČSN EN ISO 7438, "Metallic Materials-Bend Test," Czech Standards Institute, 2005.

[6] ČSN ISO 24213, "Metallic Materials-Sheets and Belt: Evaluation Method of Suspension for Flexural Bending," Czech Standards Institute, 2009.

[7] ČSN EN 13144, "Metallic and Other Inorganic Coatings: Method for Quantitative Measurement of Adhesion for Tensile Test," Czech Standards Institute, 2003.

[8] T. Blanks, "Metals Handbook: Mechanical Testing," American Society for Metals, 1985.

[9] M. Dvořák, et al., “Technology II," Academic Publishing
CERM, Ltd., Brno, 2001.

[10] V. Kreibich, "Theory and Technology of Surface Treatment," Publishing House of CTU, Prague, 1996.

[11] V. Krejčík, "Surface Treatment of Metals II," Publishing House of Technical Literature, Prague, 1988.

[12] ČSN EN ISO 20482, "Metallic Materials-Sheet and Belts-Bulge Tests According to Erichsen," Czech Standards Institute, Prague, 2004.

[13] ČSN EN ISO 1519, "Paints Substance-Bend Test (Cylindrical Mandrel)," Czech Standards Institute, 2002.

[14] M. Dvořák, M. Hušek and E. Schwarzer, "New Methods Testing of Adhesion of the Coating to Sheet Metal by Bending," Union Forges CZ j.s.c., Brno, 2010, pp. 81-84.

[15] M. Dvořák, M. Hušek and E. Schwarzer, "Testing of Adhesion of the Coating to Sheet Metal by Bending," MM Publishing Ltd., Prague, 2010, pp. 22-23.

[16] M. Hušek and M. Dvořák, "Adhesion Test of MultiFunctional Coating Al-Zn,” STU, Bratislava, 2009, pp. 63-71.

[17] M. Hušek and M. Dvořák, "Adhesion Test of MultiFunctional Coating on the Plate Using Graduated Bending Jig," Engineering Technology, No. 2, 2010, pp. 15-19.

[18] M. Klíma, Z. Muzikár, M. Dvořák and M. Alberti, "Surface Treatment by Low-Temperature Non-Isothermal Plasma at Atmospheric Pressure," 41th International Conference on Paints, University Pardubice, 2010, pp. 251262.

[19] Masaryk University, "Method of Making a Physically and Chemically Active Environment by Means of a Plasma Jet and the Related Plasma Jet," Patent EP 1077021, 2005 . 